\title{
Intensive travel time: an obligation or a choice?
}

\author{
Iragaël Joly $^{1}$ - Stéphanie Vincent-Geslin ${ }^{2,3}$
}

Received: 7 October 2014 / Accepted: 28 January 2016 / Published online: 27 February 2016

(C) The Author(s) 2016. This article is published with open access at SpringerLink.com

\begin{abstract}
This paper explores what prompts some individuals to spend a significant amount of time travelling. In the literature, travel time tends to be regarded as useless, unproductive time and, in some cases, as the worst time of the day. The actual behaviour of intensive travellers challenges this view of travel time. A mixed approach that combines quantitative and qualitative methodologies was adopted. A survival analysis of daily travel time in eight European cities gives a quantitative definition of intensive travellers. Qualitative interviews with intensive travellers explore the various dimensions of choice and/or obligation that are responsible for these extreme daily travel times. The results show that roughly $20 \%$ of the individuals in the sample for each city have long travel times (more than $100 \mathrm{~min}$ a day). The quantitative analysis also suggests that the behaviour of these individuals is atypical and cannot be explained solely by the characteristics that are considered in standard travel surveys. A qualitative sociological approach supplements the quantitative approach and illustrates that the allocation of travel time is not only determined by the activity pursued at the destination or the mode of transport but also by other factors such as personal beliefs and the perception of travel time. The positive perception of travel time as time to be used constructively or enjoyed influences
\end{abstract}

Iragaël Joly

Iragael.Joly@grenoble-inp.fr

Stéphanie Vincent-Geslin

stephanie.vincent@entpe.fr

1 INRA-GAEL, Grenoble-INP, 46 Av. Felix Viallet, 38031 Grenoble Cedex 01, France

2 LET ENTPE, Rue Maurice Audin, 69518 Vaulx-en-Velin, France

3 LaSUR, EPFL, Lausanne, Switzerland the decision to travel intensively and, above all, contributes to its long-term acceptability. A number of political issues depend on travel behaviour and therefore, to some extent, on time management. New patterns of behaviour with regard to time management help explain the expansion in the range of individual travel.

Keywords Travel time · Use of travel time $\cdot$ Survival model · Mixed approach

JEL Classification $\mathrm{R} 41 \cdot \mathrm{Z} 13$

\section{Introduction}

In the literature, travel time is sometimes considered to be the worst time of the day [27] and has been reported as being negatively correlated with happiness [56]. Nevertheless, travel time budgets have increased in several European conurbations, ${ }^{1}$ suggesting that a growing number of people are spending more time travelling and that some of them are experiencing what can be termed "extreme" travel times. This paper will examine the reasons that lead some people, to whom we shall refer as "intensive travellers", to spend so much time a day travelling. The primary concern of this paper is thus to define above what time threshold an individual becomes an intensive traveller and the determinants of this behaviour. Some seem to find pleasure, whereas others see only constraint or boredom. Based on these two contradictory observations, this paper sets out to explore intensive daily travel behaviour and to draw conclusions about what drives

\footnotetext{
${ }^{1}$ Travel time budgets are increasing, especially in The Netherlands, Great Britain, France and Switzerland [13, 22, 26, 47, 48, 62].
} 
intensive travellers to accept such extreme travel time budgets if travel time is, indeed, useless and perceived as negative.

Economic theory tends to consider travel time as derived from participation in activities. Many studies have examined travel time in relation to the types of activities pursued and their duration. Chen and Mokhtarian [11] introduced the principle of proportional allocation in a microeconomic model [3], assuming that the travel time for a given activity is determined by "travel time prices for activities", by calculating travel time based on the length of the activity using different rates depending on the type of activity. Thus, in this model, travel time is considered only as a constraint. Certain empirical studies have attempted to quantify this relationship (typically via a proportional relationship) between transportation and activity durations, based on different methods. Thus, a considerable number of studies have estimated a time price of travel [6, 7, $15,17,18,20,30,31,35,38,54,55]$.

Nonetheless, the time an individual is willing to spend travelling to and from an activity is the result of a complex process that combines a large number of compromises. Expressing travel simply in terms of price - be it temporal or monetised - (as a result of the performance of transportation systems, for instance) seems reductionist in the sense that some trips (or parts thereof) seem more arduous than others. For example, the first $10 \mathrm{~min}$ of a trip are often less negatively perceived than the last ten. Similarly, the wait for a given mode of public transportation is often perceived more negatively than the actual trip, and so on. Using non-linear relationships between travel time and activity time, Joly [25] has shown individuals' growing reluctance to accept everincreasing travel times. Moreover, this depiction of travel time as a direct cost to individuals' activity schedules is to some extent challenged by recent qualitative and quantitative research that offers another interpretation of travel time. The possible existence of a trade-off between activity time and travel time in relation to the perceived quality and utility (or uselessness) of this time should undoubtedly be considered. Studies have attempted to characterize the value of travel time, which in fact is not always viewed as wasted time that, optimally, should be reduced. Rather than a cost, travel time can be perceived as 'gifted' time during which the individual is able to engage in activities [24].

Trips and travel time have a positive use, not only because of the activities that can be done during the journey but also because of different aspects inherent to the journey (landscapes, comfort, the pleasure of driving, a break between activities, etc.) $[14,19,37,43,44,49,53,60]$. Travel time can be seen as time that has been saved, or a pleasant time where the vehicle becomes a living space in its own right $[49,51]$ and during which a variety of activities can be done, thus making it worthwhile - even productive [16, 38, 51, 59]. Travel time can even be an opportunity for doing personal activities that would be impossible at another time during the day [24]. Moreover, the information age with increased use of mobile communication technologies seems to have changed the perception of travel time and its utility, as Lyons et al. have pointed out in the case of UK train passengers [36]. Travel speed and its maximization appear not to be an objective for some travellers, as stated by O'Fallon and Wallis in their research in New Zealand [46].

To study travel time effectively - especially for intensive travellers - at the very least these two theoretical viewpoints should be considered. The methodology proposed in this article is therefore mixed in that it applies both quantitative and qualitative methods to a single research topic [21]. This proposed mixed method attempts to move beyond the usual preconceived ideas about travel time. Managing time and making schedules involve complex behaviour and choices, which put travel time at the crossroads between individuals' decisions to participate in activities and the various constraints and opportunities as regards transportation systems and facilities, as well as the perception and value given to travel time.

The following section presents the quantitative and qualitative methods used in this research. The third section, in which our findings are presented, begins by defining a criterion for identifying intensive travellers and goes on to identify and measure the determinants of travel time and finally reports on interviews with intensive travellers about their experience of travel time. In the fourth section we conclude with a discussion about several topics.

\section{Methodology}

This article is based on a mixed approach that uses both a quantitative statistical method (duration models) and a qualitative method (interviews). The quantitative method sets out to characterise the level of daily travel time that defines intensive travellers and to identify the determinants of daily travel duration.

\subsection{Quantitative method}

\subsubsection{Duration model}

The analysis of the daily travel times for our sample is based on duration models, alternatively known as survival analysis. In the activity-based literature, duration models are used to analyse both the duration of daily activities and the activity pattern structure [25]. We analyse the daily time allocated to transport (the sum of the duration of all trips), hence simplifying the daily process of time allocation to travel.

Duration model techniques are able to overcome a number of the limitations of Ordinary Least Squares (OLS) estimation. Duration data are known to be non-normal data, non- 
symmetric with a specific form. Linear regression is not robust to these violations [34].

In the framework of duration models, specific attention is given to the concept of duration dependence. Duration models consider the time variable under study as the duration of an individual in a given state and then consider the probability of leaving that state at any time. Hence, the model estimates the probability of leaving the current state as being dependent on the time spent in the state. The focus on the duration dependence dimension of the daily allocation of time to travel raises the question of the temporal dynamic of the behaviour. We can infer that, on average, this probability of leaving or stopping travel should be increasing if travel time is an undesired and unsatisfying time.

Average behaviour is modelled by defining the survival function, or the probability of a representative individual travelling for a given duration on a daily basis. The hazard rate associated with this survival represents the rate of interruption at each date. The hazard function is defined as the limit of the conditional probability of a process ending, given the elapsed time. Hence, the likelihood of daily travel time ending depends on the length of elapsed time. This probability can vary during the process.

If the hazard rate increases, the likelihood of interruption increases with the duration of travel. If it decreases, interruption is increasingly unlikely. The survival function associated with it decreases all the time, as hazard is always positive. The survival function can be concave, convex or both successively, depending on the hazard rate. Figure $1 \mathrm{a}$ and $\mathrm{b}$ illustrate two common types of hazard and survival curves. First, the monotonic increasing hazard indicates an increasing risk to stop the allocation of time to travel with the travel duration. In the

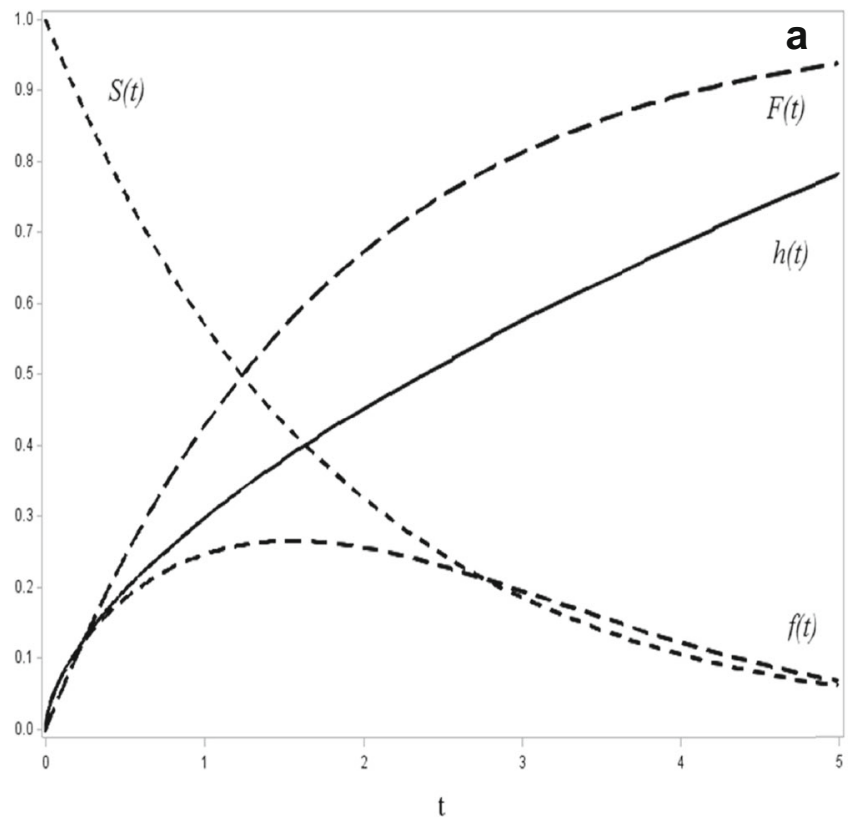

second figure, the non-monotonic hazard (increasing and decreasing) indicates a varying chance to stop the travel time. For individuals completing the corresponding travel duration, decreasing hazard would indicate a decreasing propensity or capacity to stop their travel.

The type of hazard function, therefore, has an important impact on how the process' temporal dynamic is represented. Information on the temporal dynamics of the process can be gathered directly by studying the slope of the hazard curve.

Non-parametric analysis provides more information about raw survival and hazard. The survival function is estimated using the Kaplan-Meier estimator. In the case of rounded stated times, we choose to group event times into 5-min intervals. Assuming that the hazard remains constant within each discrete period, one can then approximate the shape of the hazard function by a continuous-time step function. This method allows us to define the critical duration (i.e., the duration for which hazard is at its highest) beyond which mobile individuals are deemed to be intensive travellers.

Once the distribution has been validated, the impact of explanatory variables on survival is introduced by means of Cox's proportional hazard model. Cox's semi-parametric estimation method imposes no constraints on the form of the baseline hazard. This method is considered to be more robust than the fully parametric approach [45] as regards the estimation of the effects of covariates. Cox's model allows us to identify and evaluate the impact of the assumed determinants on hazard rate and, consequently, on the average daily travel times.

When interpreting the results of Cox's model, it should be noted that a positive regression coefficient means a greater likelihood of travelling no further, thus shortening the travel

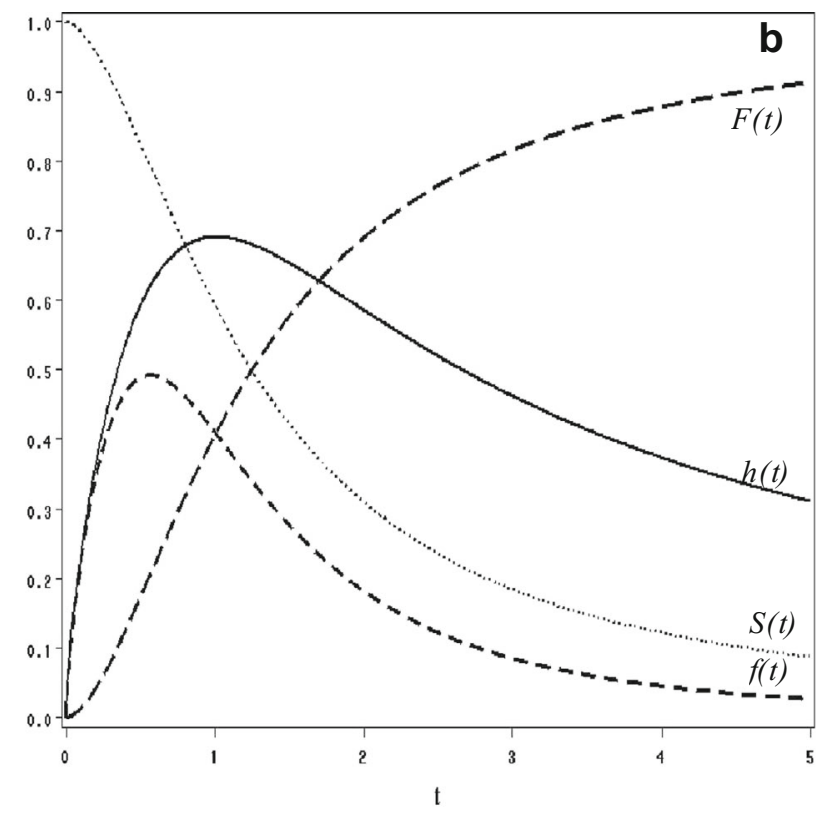

Fig. 1 a: Examples of density, $f(t)$, probability $F(t)$ and survival $S(t)$ curves associated with monotonic increasing hazard $h(t)$. b: Examples of density, $f(t)$, probability $F(t)$ and survival $S(t)$ curves associated with non-monotonic hazard $h(t)$ (increasing and decreasing) 
time budget. Conversely, a negative coefficient means a higher travel time budget.

Our third step, using a binary logit model, was to estimate the determinant of the probability of a mobile person to become an intensive traveller. We can expect that for most of the explanatory variables, the effect on the average daily travel time and on the probability of intensive travel will be equivalent.

\subsubsection{Data}

The data was provided by travel surveys conducted in eight cities in three European countries (Lyon (2006), Grenoble (2002), Rennes (2001) and Strasbourg (1997) in France, Geneva, Bern and Zurich in Switzerland (2000) and Brussels in Belgium (1999). These cities were chosen because the travel data available for them was relatively contemporary (see Table 1). Secondly, the surveys, albeit in different countries, used similar methodologies for measuring respondents' travel behaviour and activities. Finally, these cities offer great diversity in terms of socio-demographical profiles, urban morphology, density and transportation infrastructure (see Table 2 for a detailed description of these characteristics in the eight cities). Strasbourg, Zurich and Bern have effective urban and regional public transport systems and are developing a policy to optimise these infrastructures and regulate car accessibility to the city centre. The supply of urban public transport in Lyon, Grenoble, Brussels and Geneva is effective but regional transport is weak. Transport policy in these cities aims to develop public transport and road infrastructure, while simultaneously restricting car accessibility to the city centre. Public transport in Rennes is poor and the city's transport policy tends to promote road traffic.
The data collected for each country differs both in terms of response items and level of detail. Common classifications were made for trip purpose (types of activities), modes of transport used and socio-demographic characteristics. As Timmermans et al. [57] have pointed out, international comparative studies are often problematic due to the recomposition of the variables (activity patterns, transport modes, etc.). Extensive work was then done to make the data as comparable as possible and avoid the use of subjective variables [26].

Thus, activities outside the home have been divided into four categories: 1) work/training, 2) education, 3) shopping/ personal business, 4) social/leisure activities. It should be noted that only weekdays (Monday-Friday) were available in the three types of survey and thus in this analysis. The absence of Saturdays and Sundays is obviously limiting, especially for shopping and leisure trips.

\subsection{In-depth interviews with intensive travellers}

In order to understand their behaviour, experience and perceptions of travel time, qualitative research has long focused on individuals with large travel time budgets. Intensive travellers were chosen based on the amount of time they spent travelling each day (a minimum of $2 \mathrm{~h}$ ). In addition to this criterion, a diversity principle was applied when recruiting respondents. Twenty-nine interviews were conducted in three of the eight cities for which we have quantitative data (Lyon, Geneva and Brussels). Three sets of qualitative data were used in the analysis - a first set of 11 interviews done in 2008 in the Lake Geneva area, a second set of eight interviews done in France in the Lyon region in 2008 and a third set of ten interviews done in the Brussels region in Belgium, also in 2008. As the

Table 1 Characteristics of the surveys compared

\begin{tabular}{|c|c|c|c|}
\hline & France & Switzerland & Belgium \\
\hline Name of survey & Household Travel Surveys (EMD) & Microcensus 2000 & Belgian mobility survey (MOBEL) \\
\hline Year & $\begin{array}{l}1997 \text { (Strasbourg) } \\
2001 \text { (Rennes) } \\
2002 \text { (Grenoble) } \\
2006 \text { (Lyon) }\end{array}$ & 2000 & 1998-1999 \\
\hline Survey method & Household interview & $\begin{array}{l}\text { Computer-assisted telephone } \\
\text { interview (CATI) }\end{array}$ & $\begin{array}{l}\text { Mail-in survey with additional follow-up } \\
\text { by telephone, if necessary }\end{array}$ \\
\hline Respondents & All persons in household 5 years or + & $\begin{array}{l}1 \text { person }(+6 \text { years.) per household } \\
\text { (if household }<4 \text { people); if }>4,2 \\
\text { people surveyed }\end{array}$ & All people in household +6 years. \\
\hline Days of trips & $\begin{array}{l}\text { All trips made on the day (weekday) } \\
\text { preceding the day of the survey }\end{array}$ & $\begin{array}{l}\text { All trips made } 1-2 \text { days before } \\
\text { the survey date } *\end{array}$ & All trips made the day before the inquiry * \\
\hline Survey period & $\begin{array}{l}\text { A reference day over a period of several } \\
\text { months in a year (October to May) }\end{array}$ & A reference day over an entire year & $\begin{array}{l}\text { A reference day over a period of several } \\
\text { months in a year (October to May) }\end{array}$ \\
\hline
\end{tabular}

Source:[23, 26, 47]

* The present study considers only weekdays 
Table 2 Geographic and transport system indicators and sample size for the 8 cities

\begin{tabular}{|c|c|c|c|c|c|}
\hline City & Area covered by survey $\left(\mathrm{km}^{2}\right)$ & Number of zones/municipalities & Average surface area $\left(\mathrm{km}^{2}\right)$ & Population & Sample size \\
\hline Brussels & 557 & 33 & 16.9 & $1,309,478$ & 982 \\
\hline Grenoble & 310 & 36 & 8.6 & 386,886 & 4934 \\
\hline Lyon & 490 & 76 & 6.4 & $1,226,052$ & 9465 \\
\hline Rennes & 609 & 46 & 13.2 & 358,561 & 6900 \\
\hline Strasbourg & 305 & 32 & 9.5 & 449,036 & 3317 \\
\hline Bern & 422 & 36 & 11.7 & 333,334 & 1163 \\
\hline Geneva & 228 & 42 & 5.4 & 410,261 & 1688 \\
\hline Zurich & 906 & 99 & 9.2 & 983,937 & 1818 \\
\hline City & Public transport system (1) & Parking limitation & Cycling infrastructure & \multicolumn{2}{|c|}{ Policy on car access to city centre } \\
\hline Brussels & $\mathrm{S}+\mathrm{T}+\mathrm{B}$ & Weak constraint & Medium development & \multicolumn{2}{|c|}{ Favourable to car } \\
\hline Grenoble & $\mathrm{T}+\mathrm{B}$ & Weak constraint & Medium development & \multicolumn{2}{|c|}{ Favourable to car } \\
\hline Lyon & $\mathrm{S}+\mathrm{T}+\mathrm{B}$ & Weak constraint & Low development & \multicolumn{2}{|l|}{ Incentive } \\
\hline Rennes & $\mathrm{B}$ & Weak constraint & Low development & \multicolumn{2}{|l|}{ Incentive } \\
\hline Strasbourg & $\mathrm{T}$ & Weak constraint except in city centre & High development & \multicolumn{2}{|l|}{ Restrictive } \\
\hline Bern & $\mathrm{T}+\mathrm{B}$ & Strong constraint & High development & \multicolumn{2}{|l|}{ Restrictive } \\
\hline Geneva & $\mathrm{S}+\mathrm{T}+\mathrm{B}$ & Weak constraint except in city centre & Medium development & \multicolumn{2}{|c|}{ Favourable to car } \\
\hline Zurich & $\mathrm{S}+\mathrm{T}+\mathrm{B}$ & Strong constraint & High development & \multicolumn{2}{|l|}{ Restrictive } \\
\hline
\end{tabular}

(1) Subway (S); Tramway (T); Buses (B)

interviews were conducted in French, we decided not to translate respondents' statements verbatim but to report the contents of their replies in the analysis in order to avoid distorting their statements.

The interviews were conducted based on a qualitative, comprehensive method using life story interviews [1, 5, 12]. The qualitative method was chosen precisely for its comprehensive dimension $[4,32]$ because it seemed to be the best way to bring out the trade-offs that were important for respondents and influential in their decision-making. Although many studies mention teleporting, the preference for this hypothetical option was not tested during interviews [9, 46, 50]. We agree with O'Fallon and Wallis [46] that travellers, especially intensive travellers, tend to answer this question with reference to their own travel constraints, in particular the location of their job and home.

From the standpoint of data collection, a number of sociospatial disparities exist between the three countries. Belgium and Switzerland are similar in several respects in which France differs. First, Switzerland and Belgium are comparable in size and small and thus conducive to travel. Residents of these countries are less inclined to move within their country than are the French (for example, when changing jobs, because travel distances are shorter and more feasible on a daily basis). Moreover, a language barrier divides both Switzerland and Belgium, which is another obstacle to residential relocation. Thus, Switzerland and Belgium are commuter countries. However, the sheer size of metropolitan France - which covers a greater area and has longer distances - is an obstacle to intensive travelling practices, although the development of high speed rail lines has done a great deal to provide a rapid connection between remote areas. Spatial constraints and geographical remoteness tend to encourage residential relocation rather than the commuting practices found in Switzerland and Belgium. In France, intensive travel practices are reflected in the travel practices of residents living on the periphery of major cities, as is the case in Lyon.

\section{Results}

\subsection{Defining intensive travellers}

The data collected in each of the cities in the study provide the duration of each trip made by the individuals in the samples. The daily travel time budget was then calculated as the sum of the duration of all trips made during the day. The average travel time budgets (for the mobile population) are relatively high (Table 3). More specifically, the proportion of individuals whose travel time budget exceeds $100 \mathrm{~min}$ (or even $2 \mathrm{~h}$ ) is not marginal (around 10-25\% of the mobile population).

Intensive travellers are defined in this study as individuals who travel more than $100 \mathrm{~min}$ per day. It is worth noting that the previous studies of such behaviour focus on commute distance [10, 39] and commute time [40], thus restricting their definition of extreme travel time to commuting. This paper analyses travel movements over the whole day. By including all the activities pursued in a day, travel time for constrained activities is balanced against travel time for discretionary activities. Extreme travel time is identified no longer in terms of 
Table 3 Mean and median daily travel time budgets and number of daily trips made by the mobile population

\begin{tabular}{|c|c|c|c|c|c|c|c|c|}
\hline \multirow[t]{2}{*}{ Cities } & \multicolumn{3}{|c|}{ Number of trips } & \multicolumn{3}{|c|}{ Daily travel time budgets (min.) } & \multicolumn{2}{|c|}{ Intensive travellers } \\
\hline & Mean & Median & $\mathrm{N}$ & Mean & Median & $\mathrm{N}$ & $\%>100 \min$ & $\%>120 \mathrm{~min}$ \\
\hline Brussels & 3.78 & 3 & 979 & 67.82 & 55 & 979 & 19.86 & 11.85 \\
\hline Grenoble & 4.64 & 4 & 4291 & 70.30 & 60 & 4291 & 20.23 & 11.77 \\
\hline Lyon & 3.87 & 4 & 9445 & 70.79 & 60 & 9445 & 21.01 & 12.33 \\
\hline Rennes & 4.56 & 4 & 4818 & 65.23 & 60 & 4818 & 15.09 & 8.43 \\
\hline Strasbourg & 5.66 & 5 & 1871 & 77.51 & 70 & 1871 & 23.75 & 14.59 \\
\hline Bern & 3.84 & 4 & 1051 & 67.08 & 58 & 1051 & 19.54 & 11.99 \\
\hline Geneva & 4.08 & 4 & 1639 & 70.66 & 60 & 1639 & 22.58 & 13.67 \\
\hline Zurich & 3.76 & 4 & 1653 & 71.59 & 61 & 1653 & 23.21 & 14.70 \\
\hline
\end{tabular}

mere distance travelled (which, at least in part, depends on access to high speed transportation systems) but in terms of the daily amount of time allocated to travel. Nevertheless, this focus on travel time includes long distance commuters de facto.

It is debatable at what point travel time budgets should be considered to be "high". Using a quantitative method to define this threshold, travellers were defined to be "intensive" based on the amount of time they spent travelling each day. Rather than engaging in a discussion about the choice of the appropriate quantile, survival analysis methods were chosen. Modelling the hazard rate identified the duration dependence of the process of allocating time to travel. As the graphs show (Fig. 2), the hazard rate is non-monotonic and decreases for all cities at around 100-120 min. This specific shape of the hazard indicates that there is a time threshold beyond which the hazard rate of individuals still engaged in the process (travel, in this case) decreases at each date. Thus, there is less and less chance of them interrupting their travel and, consequently, their resistance to long travel time is greater.

However, the survival rate indicates that the number of "survivors" exceeding this threshold is not insignificant; 15$25 \%$ of travellers travel for more than $100 \mathrm{~min}$ and $10-15 \%$ for more than $120 \mathrm{~min}$ (Table 3). The findings for the eight cities thus converge, providing a quantitative threshold with which to define intensive travellers as well as the recruitment criteria for respondents for the qualitative survey.

\subsection{The determinants of intensive travelling}

Both the quantitative and the qualitative method of analysis confirmed the same determinants of intensive travelling. First, we quantified the effects on average travel time (through the hazard rate) and on the probability of being an intensive traveller of the determinants available in the travel surveys, insofar as this was possible. Second, our investigation of the determinants of travel behaviour was informed by the qualitative interviews we conducted, which highlight the role of a certain number of traits linked to the individual and the household.
First, three types of determinants were identified, consistent with those found in the literature: the household's socio-economic characteristics; the individual's travel characteristics and activity patterns; and the day of the week.

In general, the results are consistent with those found in the literature on daily travel time (see [25, 42]). Table 4 shows the results of the estimation of the Cox and the logit models. Most of the estimated coefficients are significant. The signs of the coefficients are the same in the two estimations.

i - Households' socio-economic characteristics

First of all, households' socio-economic characteristics influence daily travel times and can thus be considered to be a determinant of intensive travel (Table 4). Our estimation results show that on average men's hazard rate is $8.6 \%$ lower than women's (Cox model: $\beta=-0.089$, hazard ratio $=0.914, p$-value $<0.001)$ and that they also have a higher probability of intensive travel (logit model: $\beta=0.3212$, odds ratio $=1.379, p$-value $<0.001$ ). Individuals of working age (over 15 years) have longer travel times than older people (aged 65 years and over) and a higher probability of being intensive travellers, whereas younger people (aged between 5 and 14 years) have lower daily travel times. The dummy variables for the cities impact daily travel times and the probability of intensive travel in the same direction. All else being equal, the daily travel time and the probability of intensive travel are the lowest in Rennes, which is the city in our sample that most favours car travel, buses providing the only public transport. In increasing order of daily travel times, there follows: Strasbourg, Grenoble, Brussels, Lyon, Bern, Geneva and Zurich. Individuals' occupations also affect their daily travel time and their probability of intensive travel. Nonetheless, there are disparities between the countries (captured by the dummy variables that 
BRUSSELS 2006

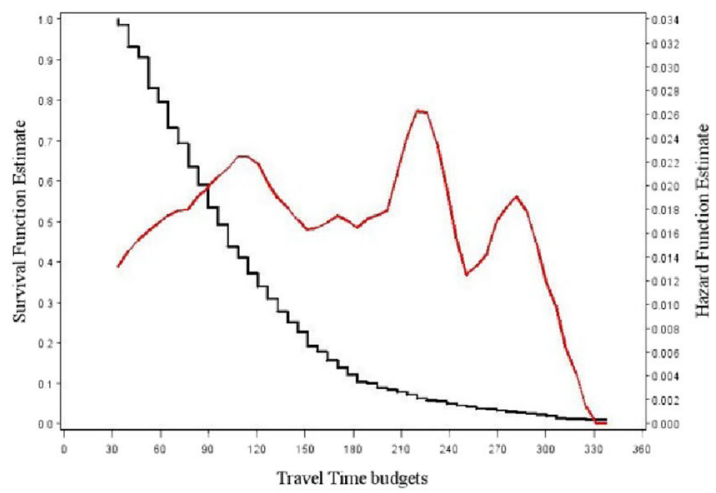

LYON 2006

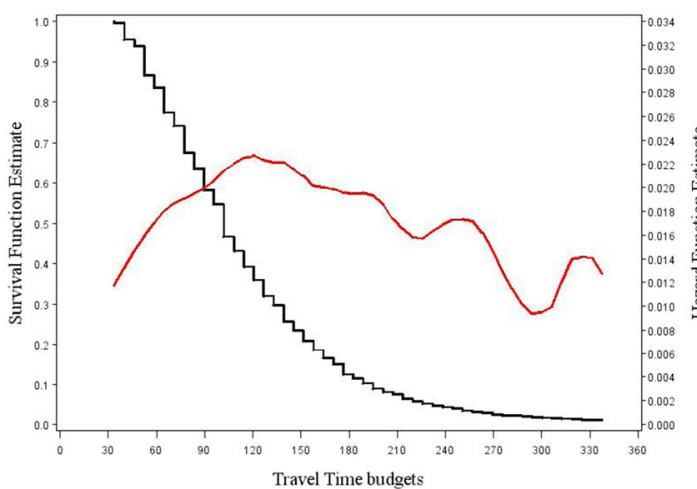

STRASBOURG 1997

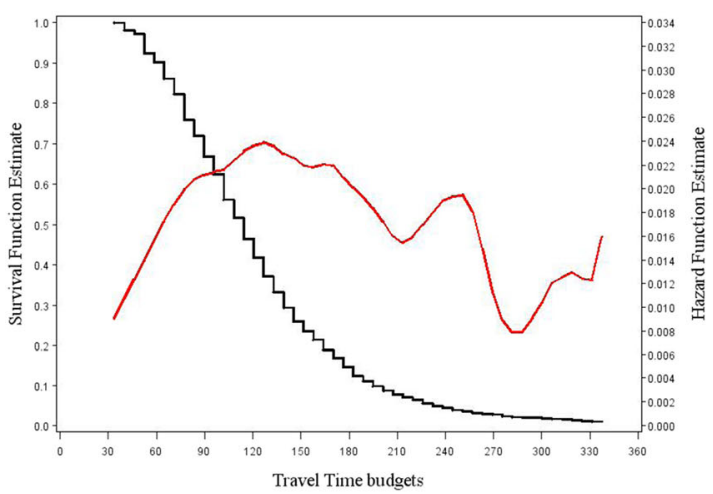

GENEVE 2000

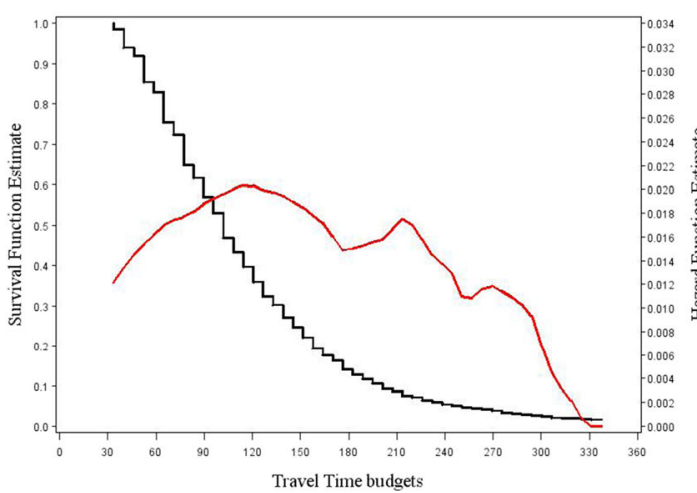

GRENOBLE 2001

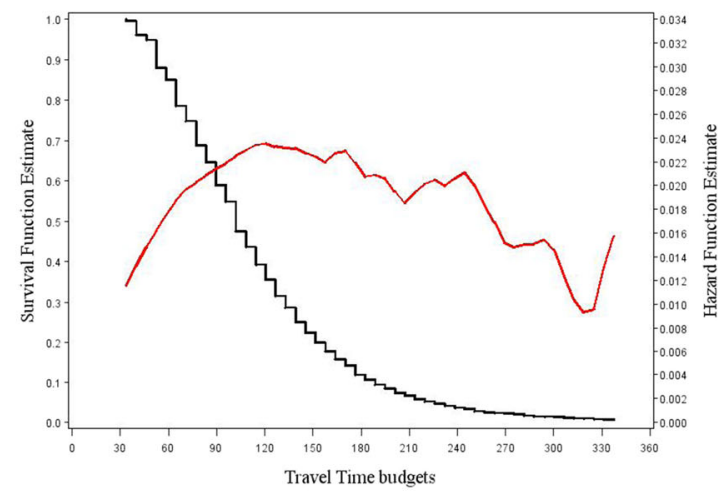

RENNES 2000

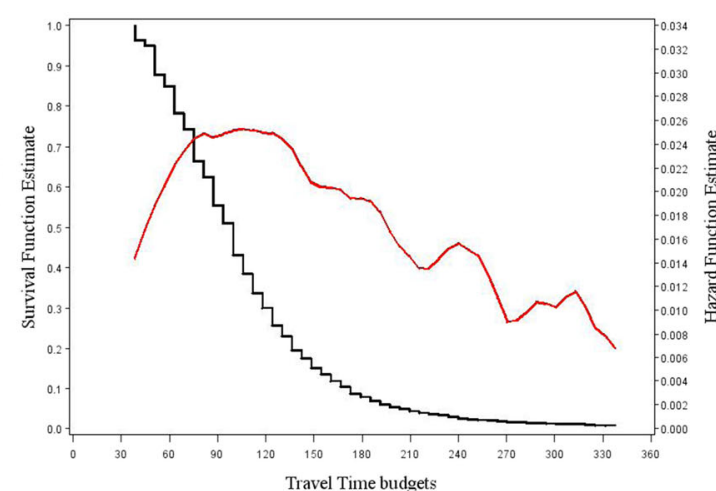

BERN 2000
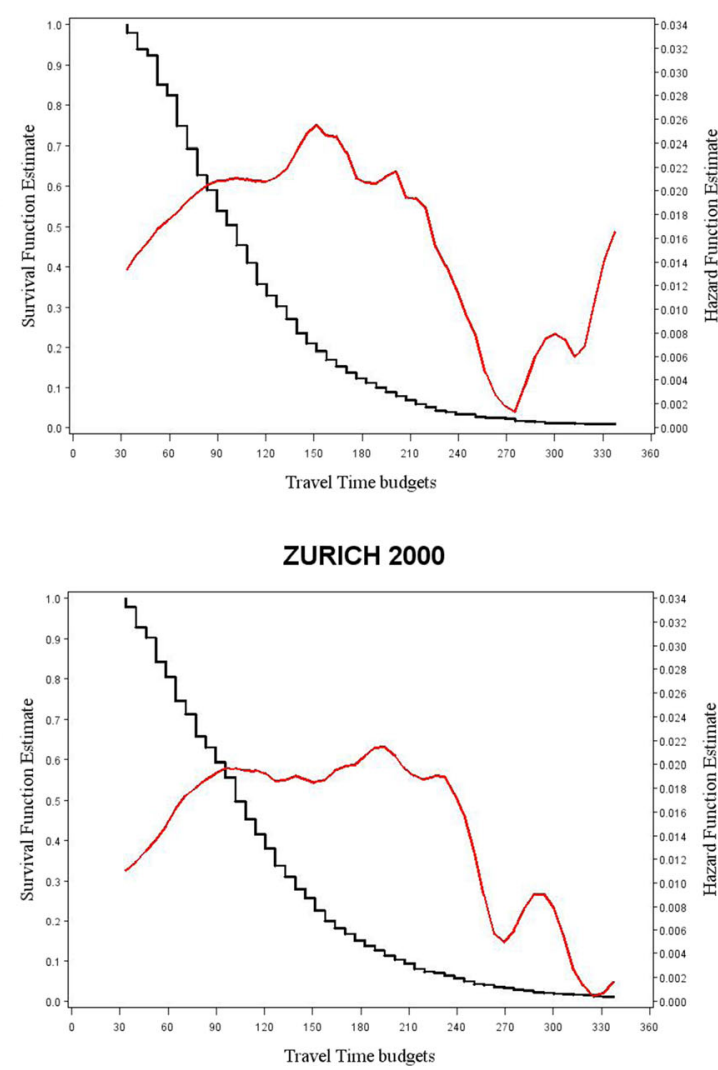

Fig. 2 Estimated survival and hazard curves for each city (in red: estimated hazard curve; in black: estimated survival curve) 
Table 4 Results of the estimation of the semi-parametric Cox model and the LOGIT model

\section{Cox model}

Variables

Socio-demographic attributes

Gender (female $=$ ref.)

14 years old and under

Between 15 and 25 years of age

Between 25 and 55 years of age

Between 55 and 65 years of age

65 years of age and over

Employed in Belgium

Employed in France

Employed in Switzerland

Unemployed

Presence of children under 12 years of age $(1 / 0=$ ref.)

Couple $(1 / 0=$ ref. $))$

Car owners $(1 / 0=$ ref. $))$

Spatial indicators

Brussels

Grenoble

Rennes

Strasbourg

Lyon

Geneva

Bern

Zurich

Mobility and activity indicators

Number of daily trips

Daily duration of activity:

Work

School/training

Shopping/Personal business

Leisure activities

Monday

Tuesday

Wednesday

Thursday

Friday

Logit model

Variables

Socio-demographic attributes

Gender (female $=$ ref.)

14 years of age and under

Between 15 and 25 years of age

Between 25 and 55 years of age

Between 55 and 65 years of age.

$65 \leq$ Age

Employed in Belgium

Employed in France

Employed in Switzerland

Unemployed
Parameters

Hazard ratios

$-0.0899$

$* * *$

0.914

0.3709

$-0.3157$

$-0.1347$

$-0.1253$

ref.

$-0.1892$

0.0689

0.2667

ref.

0.1228

$-0.0185$

0.0837

0.4077

0.4393

0.5474

0.4540

0.2518

0.1040

0.1415

ref.

$-0.1541$

$* * *$

$-0.0004$

$-0.0001$

$-0.0096$

$-0.0015$

0.0752

0.0556

0.0197

0.0414

ref.

Parameters

Odd ratios

0.3212

$-0.7586$

0.5843

0.2799

0.2592

ref.

0.2546

0.1818

$-0.6764$

ref.
0.857

1.449

0.729

0.874

0.882

0.828

0.933

1.306

1.131

0.982

1.087

1.503

1.552

1.729

1.575

1.286

1.110

1.152

1.000

1.000

0.999

0.999

1.078

1.057

1.020

1.042

1.379

0.468

1.794

1.323

1.296

1.290

1.199

0.508 
Table 4 (continued)

\begin{tabular}{|c|c|c|c|}
\hline Presence of children under 12 years of age $(1 / 0=$ ref. $)$ & -0.3086 & $* * *$ & 0.734 \\
\hline Couple $(1 / 0=$ ref. $))$ & -0.0167 & & 0.983 \\
\hline Car owners $(1 / 0=$ ref.) $)$ & -0.2422 & $* * *$ & 0.785 \\
\hline \multicolumn{4}{|l|}{ Spatial indicators } \\
\hline Brussels & -0.8371 & $* * *$ & 0.433 \\
\hline Grenoble & -1.1047 & $* * *$ & 0.331 \\
\hline Rennes & -1.4236 & $* * *$ & 0.241 \\
\hline Strasbourg & -1.1204 & $* * *$ & 0.326 \\
\hline Lyon & -0.6450 & $* * *$ & 0.525 \\
\hline Geneva & -0.2284 & $* *$ & 0.796 \\
\hline Bern & -0.2879 & $* *$ & 0.750 \\
\hline Zurich & ref. & & \\
\hline \multicolumn{4}{|l|}{ Mobility and activity indicators } \\
\hline Number of daily trips & 0.2939 & $* * *$ & 1.342 \\
\hline \multicolumn{4}{|l|}{ Daily duration of activity: } \\
\hline Work & -0.0001 & & 1.000 \\
\hline School/training & -0.0002 & & 1.000 \\
\hline Shopping/personal business & 0.0011 & $* * *$ & 1.001 \\
\hline Leisure activities & 0.0021 & $* * *$ & 1.002 \\
\hline Monday & -0.2283 & $* * *$ & 0.796 \\
\hline Tuesday & -0.1213 & $*$ & 0.886 \\
\hline Wednesday & -0.1089 & $*$ & 0.897 \\
\hline Thursday & -0.1536 & $* *$ & 0.858 \\
\hline Friday & ref. & & \\
\hline Intercept & -2.7392 & $* * *$ & \\
\hline
\end{tabular}

$N=25747, p$-value: $* * *<0.01 ; * *<0.05 ; *<0.1$

combine country and occupation ${ }^{2}$ ). Workers in Belgium have longer daily travel times than French workers, while Swiss workers have shorter daily travel times than French workers. Conversely, the presence of children under the age of 12 in a household tends to reduce the daily travel time and the probability of intensive travel. Similarly, carowning households tend to have shorter daily travel times and a lower probability of intensive travel.

ii - Trip characteristics, activity patterns and day of the week

The characteristics of individuals' trips and activity schedules also determine intensive travelling, as a greater number of trips increase the daily travel times and the probability of intensive travel.

The qualitative and quantitative results are consistent in showing differences in daily travel time budgets according to the day of the week, resulting in a degree of regularity and a weekly cycle (commonly inferred from cross-sectional data). The qualitative survey, however, provides insight into this question. This regularity indicates increasing travel time budgets during the week and

\footnotetext{
$\overline{2}$ The databases do not allow for the creation of more refined transverse classes. Thus all occupations (executives, employees, labourers, etc.) must be treated as a single category, resulting in the assumption of the homogeneity of travel practices between cities from the same country. On the contrary, unemployed persons are in heterogeneous situations in and between cities and countries. Therefore we take the unemployed status as reference. Here again, qualitative analysis would provide more detailed information and new perspectives.
}

increasing probability of extreme travel. Travel times are lower at the beginning of the week than on Wednesday and Friday, which can be explained by the fact that intensive travellers are more likely to engage in leisure activities at the end of the week so as to limit fatigue. Yoann, for instance, prefers to go out with his friends on Thursday night, because after Thursday there is only one working day left in the week. He avoids going out on Tuesdays or Wednesdays because, if he did, he would be likely to be tired for the rest of the week.

The duration of activities outside the home (work, job training, school, leisure activities, shopping and personal business) significantly increases daily travel times. Nevertheless, the probability of intense travel seems to be significantly and positively correlated only with the duration of leisure, shopping and personal business activities, indicating that intense travel may be the result of a specific activity pattern and duration. This result therefore indicates that, in certain cases, longer periods of travel time may be chosen. For methodological reasons (sample size and lack of statistical representativeness), it is difficult to take these dimensions into account in the qualitative survey.

Many people's daily travel time budgets increase once or twice a week due to activities outside the workplace. In most cases, these activities are pre-planned and regular (on a given day). John's daily travel time increases by roughly 20 min twice a week because of football practice. In addition to a 50-min train ride, Thomas also 
drives 40-50 min once a week to attend rehearsals of his music group. Anne's daily journey also increases by 10 min twice a week when she goes to pick up her dry cleaning.

The idea of the opportunity cost of travel time was also perceptible in the interviews. Intensive travellers' free time for other activities is clearly limited. This increased constraint in turn causes them to modify certain aspects of their trips. The first effect relates to the difficulty of going home before doing other occasional activities. These additional trips are therefore combined with routine trips and, consequently, potentially change the selected mode of transportation. For instance, rather than take the train to work as she normally does, Rachel takes her car on those days when she has planned leisure activities in Lausanne after work.

The interviews also show that the organization of these additional trips has repercussions on the organization of the other days. John and Thomas leave work early on days when they have their musical and sporting activities and must, therefore, make up these hours by working later on the other days of the week. In this way, secondary activities can influence daily travel time budgets for the entire week. Such daily variations in travel time budgets have been observed in numerous quantitative studies. Another aspect of this link between secondary activities and travel time is the postponing of leisure activities and home management to the weekend. In the case of home management, it is also interesting to note that shopping and household chores can also be transferred to another member of the household or another party. For example, it is Emilie's husband, also an intensive traveller, who does the family grocery shopping on Friday, as he only works 4 days a week. They have also chosen to hire a cleaning woman to unburden themselves of this task. Therefore, activity time management during the week cannot be analysed solely from an individual perspective, as intensive travelling affects the activity schedules of all the members of the household.

Thus, several determinants of intensive travelling can be identified in the qualitative interviews and are statistically verifiable via the quantitative data. The two methods are consequently complementary in identifying and fleshing out the factors that explain high travel time budgets.

\subsection{Making use of travel time as a rationale for intensive travelling}

The interviews shed light on some of the aspects of intensive travelling that do not appear in travel surveys and/or which are more difficult to grasp quantitatively. In view of the respondents' social histories, the life story interviews indeed show that intensive travelling falls somewhere between life choices (most notably family and residential) and career choice [54]. Residential and social anchorage, the pursuit of a career into which the individual puts a great deal or about which he or she is enthusiastic or the desire to climb the career ladder are determinants of intensive travelling, be it short- or long-term. Jean-Pierre, for instance, chooses to continue his intensive travelling so that he can keep on doing the research work about which he is so passionate. In such situations, intensive daily travelling seems to be an adjustment variable between the individual's personal and professional lives.

Furthermore, travel time - using it, making it useful and how it is perceived - is one of the reasons for choosing to travel intensively. Indeed, travel time is not spent just moving from $\mathrm{A}$ to $\mathrm{B}$, different activities can be performed during this time that imbue it with meaning (productivity, relaxation, transition, sociability, avoidance or excitement) [16]. Whatever the activity or meaning behind it, activities themselves say nothing about intensive travellers' perception of travel time, as activities alone are not enough to turn travel time into quality time. As Russell [52] has pointed out, activities that involve "doing nothing", such as gazing ahead or out the window, may be greatly valued. Activities and inactivity both have meaning for passengers and give a value to travel time. Experienced time [61] could differ from real time. The distortion between experienced and real time creates various perceptions of travel time on a scale whose extremes are the perception of "time to kill" and time to enjoy. Between these two extremes, a median perception of travel time is to optimise it.

1) Firstly, for some intensive travellers, travel time is simply time to kill. In this case, experienced time is worse and longer than real time leading to a very negative perception of travel time. They consider that this time is wasted and useless, consequently engaging in activities simply to make the time pass more quickly. While these activities in some ways help to make up for a lack of free time, these travellers nonetheless feel they could do more activities and do them more effectively if they did not do them during their trips. Some travellers, for example, say they have trouble working on the train because of the people around them and the noise. Others are too tired to work on their way home and can only do so effectively in the morning. Finally, drivers cannot fully take advantage of their travel time because of the need to concentrate on the driving task, especially on highways.

2) Next, some intensive travellers optimise their travel time by doing activities during their trip that could be done elsewhere, at another time. Activity optimisation is consistent with some other studies on travel time use conducted on all types of travellers $[46,52]$ but it is particularly 
relevant to intensive travellers who have busy schedules. Intensive travellers very often use their travel time as an extension of work time $[16,41]$. This optimisation of travel time is only possible, however, for intensive travellers whose jobs are mobile. Other types of activities can also be done on the train in order to streamline the daily routine. Some travellers use this time to eat, especially in the morning. Others use it to sleep, thus in part compensating for the lack of sleep that results from long travel times. Finally, some use this time to finish getting ready for work, especially for putting on makeup.

3) A third and extremely positive way of perceiving travel time is to see it as additional time or time to enjoy. In this case, the activities done during the trip are activities the traveller would not have time to do otherwise and that are made possible by the very existence of a time set aside expressly for them. These activities can be personal or professional. Marie and Franck take time to read during their journey on public transport, claiming they would not have time to do so otherwise. In such cases, intensive travellers see their travel time as a personal opportunity - valuable, enjoyable, time - not the worst time of the day at all [24, 28, 29]. The results of some other studies concur with this: the increasing use of mobile communication tools helps to make trips more pleasant for travellers [38]. In addition, commuters in New Zealand would be likely to increase their daily commute time if they could have the pleasure of walking or cycling during their trips [49]. Commuters' experience of time seems to be compressed through the usefulness and pleasure of travelling.

Travellers' perception of travel time can affect their decision to become an intensive traveller, or at least to continue to be one, as well as their modal choices. Thus, when intensive travelling is experienced as a waste of time, individuals implement strategies to stop the practice (changing jobs, moving or travelling to their place of work once a week). In our survey, Yoann, who travels between Grenoble and Lyon (more than $100 \mathrm{~km}$ ), was about to change jobs when we met him, so as to end the long car journeys that he saw as a waste of time. The perceived quality of travel time also depends on the mode of transportation used and can therefore influence the modal choice of intensive travellers. ${ }^{3}$ Thus, some travellers choose to spend more time travelling to be able to take full advantage of their travel time, using public transportation most notably. This trend is reinforced by certain beliefs and environmental values. Patrick, out of concern for the environment, takes the bus instead of driving to the station, where he then takes a local train to work. In this way, transportation supply is

\footnotetext{
3 The role of the basic function of travel on modal choices and the likelihood of a modal shift was most notably highlighted by Diana [14].
}

undoubtedly one of the factors that affects the decision to travel intensively.

\section{Discussion}

Quantitative data from eight European cities has enabled us to propose a definition of intensive travel and measure its extent. Using quantitative analysis, we determined the time threshold above which travel is deemed to be intensive. Starting with a daily travel time budget of 100-120 min, individuals have a decreasing hazard rate. In other words, above and beyond $120 \mathrm{~min}$, intensive travellers are more likely to travel for even longer than other people and this trend remains strong and decreases at a slower rate than for other travellers. The quantitative definition of this threshold served as a recruitment criterion for our interviews. The determinants of intensive travelling then emerged from a cross analysis of the two methods. Firstly, individuals' socio-economic characteristics influence intensive travelling, which is more common among men and employed persons and rarer among individuals with children. Secondly, the number of trips and the duration of activities outside the home also tend to increase daily travel times. Specifically, the duration of activities (leisure, shopping and/or personal business) tends to increase the probability of being an intensive traveller. Thirdly, activities done during the week on a regular basis also increase daily travel time budgets and create regular weekly cycles. Finally, the qualitative method has opened up discussion on how travel time is experienced in order to help explain intensive travelling. The hypothesis stemming from this qualitative data is that a positive perception of daily travel time encourages intensive travelling practices.

Despite the diversity in characteristics of the studied cities (in terms of urban morphology, density, transport system, etc.), we find regularities in the level of daily travel time and the indicators of intense travel. This result casts doubt on the impact of urban morphology on travel behaviour. Approximately $20 \%$ of the mobile population spent more than $100 \mathrm{~min}$ a day travelling in each of the cities in our sample.

Common to all the cities and consistent with the results found in the literature, the interviews demonstrate that the determinants identified here are meaningful within the context of individuals' practices. Conversely, the hypotheses we have made based on the results of the interviews have been quantitatively confirmed using statistical data. The mixed method we propose has, therefore, led to the successful crossvalidation of the results by triangulation and complementarity for a single subject: intensive travellers [8, 58].

Our results challenge the findings of studies that claim that time spent travelling is considered to be the worst time of the day. Considering travel time as the worst time of the day 
implies that individuals only endure it. This is a very normative vision of travel time because it is possible to carry out many activities during a journey and also because travel time is not perceived in this negative way by intensive travellers.

The qualitative interviews especially show that this time can be useful, as individuals can then optimise their time and carry out some of the activities in their daily routine. What is more, this time has an intrinsic value of its own, as it gives other individuals the opportunity to carry out additional activities they would not be able to do otherwise. Returning to Mokhtarian and Salomon's [43] hypothesis, the value of travel time can come from three sources: the value of activities performed at the destination, the intrinsic value of the trip and the value of activities done during the trip.

Studies of long-distance commuters - one particular type of intensive traveller - highlight their ability to use travel spaces for a variety of activities. Commuters between Rouen and Paris and between Tours and Paris in turn transform trains into bedrooms (when they rest or sleep), living rooms (when they listen to music or watch films), kitchens (when they eat) and bathrooms (when they put on makeup) $[2,41]$. Means of transportation become mobile, moveable workspaces. For commuters, trains are productive spaces where they can work during their trip, in large part thanks to laptop computers [41]. Individuals who travel mainly by car can also turn their automobiles into mobile offices by calling clients, colleagues or secretaries, reading e-mails or printed documents and finalizing visits during their commute [33]. Thus, travel time can be put to various kinds of use (productive use, relaxing, or social activities), or simply be enjoyed for its intrinsically emotional and recreational dimensions, regardless of the mode used [16].

Activities that are undertaken during trips can also have an intrinsic value depending on the perceived quality of this travel time. Among intensive travellers, those who choose long trips and use their time constructively challenge the idea that travel time is merely tolerated. This type of behaviour raises issues for transport policy. Our results suggest that intensive travel behaviour is, at least partly, explained by the perception of travel time and its cost. Transport policy needs to adopt a more subjective notion than simple monetary cost. On the one hand, policies aiming to impact modal choice need to consider comfort when analysing competition between modes. On the other hand, comfort affects the choice of residential location and of the travel destinations but does not seem to reduce time and distance travelled.

The motivation for enduring a constraint of this type may be the outcome of social factors such as transportation inequalities and factors linked to income, gender and location. In addition, a number of political issues are related to travel behaviour and therefore, to some extent, on time management. For example, the expansion of the range of personal travel brought about by automobile access and the development of rail corridors around major cities is responsible for urban sprawl and peri-urbanization. Behaviour as regards time management adds new explanations for these phenomena in addition to classical factors such as access to greater speed and pressure from the housing market etc.

Our results provide additional information about the behaviour of intensive travellers in particular and travel behaviour in general. The results of the qualitative interviews suggest that a positive perception of travel time as worthwhile and enjoyable time influences the decision to travel intensively and, above all, contributes to its long-term acceptance. These statements seem to be consistent with other studies on the topic conducted in New Zealand and the UK [36, 46, 52], showing that the increasing use of mobile technologies may favour a perception of travel time as being more worthwhile [36].

Longitudinal data collected in Switzerland, France and Belgium that goes beyond life interviews to look at practices and perceptions at several points during an individuals' life trajectory might support this hypothesis. Gathering information on these dimensions of travel time would provide an opportunity to confirm both the results of the interviews quantitatively and the importance of the impact of the perception of travel time on travel behaviour. Methodologically, this means not only considering the activities done during travel but also how they are perceived. From a theoretical standpoint, answering such questions means rethinking the very question of the value of trips: must they be productive in order to have a positive value? Does travel time only have value in the economic sense of the term?

Acknowledgments We would like to thank Predit and the ANR for funding these research projects. We would also like to thank Karl Littlejohn as well as our three project partners, LET in Lyon, LaSUR in Lausanne and GRT in Namur. Also thanks to two anonymous referees for their very useful suggestions.

Open Access This article is distributed under the terms of the Creative Commons Attribution 4.0 International License (http:// creativecommons.org/licenses/by/4.0/), which permits unrestricted use, distribution, and reproduction in any medium, provided you give appropriate credit to the original author(s) and the source, provide a link to the Creative Commons license, and indicate if changes were made.

\section{References}

1. Atkinson R (2002) The life story interview. In: Gubrium JF, Holstein JA (eds) Handbook of interview research: context and method. Sage, Thousand Oaks, pp 121-140

2. Beauvais Consultants (2007) Recherche sur le développement de la grande vitesse et de la birésidentialité, rentrer chez soi chaque soir ou une fois par semaine? PREDIT research report, GO n ${ }^{\circ} 1$ « Mobilité, territoires et développement durable », Université François Rabelais SPVE / ETIcS

3. Beckmann MJ, Golob TF (1972) A critique of entropy and gravity in travel forecasting. In: Newell GF (ed) Traffic flow and transportation. American Elsevier, New York, pp 109-117 
4. Berg B (2003) Qualitative research methods for the social sciences. Lavoisier

5. Bertaux D (2005) Les récits de vie. Paris, Armand Colin, 2ème édition

6. Bhat CR, Guo JY, Srinivasan S, Sivakumar A (2004) Comprehensive econometric microsimulator for daily activitytravel patterns. Transp Res Rec 1894:57-66

7. Bhat CR, Misra R (1999) Discretionary activity time allocation of individuals between in-home and out-of-home and between weekdays and weekends. Transportation 26(2):193-209

8. Bryman A (2004) Social research methods, 2nd edn. Oxford University Press, Oxford

9. Calvert T, Avineri E (2011) Who wants to commute more and why? Exploring the positive utility of the commute. PROJECT: J Dep Plann Archit 3:68-69

10. Champion TM, Coombes B (2008) Migration and longer distance commuting in rural England. Reg Stud 42:1-15

11. Chen C, Mokhtarian PL (2006) Tradeoffs between time allocations to maintenance activities/travel and discretionary activities/travel. Transportation 33(3):223-240

12. Coninck F, Godard F (1990) L'approche biographique à l'épreuve de l'interprétation, Les formes temporelles de la causalité. Revue française de sociologie, XXXI-1, janvier-mars 23-55

13. Department for Transport (2010) Transport trends: 2009 edition. Transport Statistics: DfT, London 178

14. Diana M (2006) Utilité primaire des déplacements et multimodalité: conception et réalisation d'un outil d'enquête novateur. RTS Rech Transp Sécur 93:1-16

15. Dijst M, Vidakovic V (2000) Travel time ratio: the key factor for spatial reach. Transportation 27(2):179-199

16. Flamm M (2004) La mobilité quotidienne dans la perspective de la conduite de vie. In: Montulet B, Kaufmann V (eds) Mobilités, fluidités... libertés ? Publication des Facultés Universitaires StLouis, Bruxelles, pp 71-94

17. Golob TF, Mcnally MG (1997) A model of activity participation and travel interactions between household heads. Transp Res B 31(3):177-194

18. Goulias KG, Brög W, Erl E (1998) Perceptions in mode choice using the situational approach: a trip by trip multivariate analysis for public transportation. The 77th Annual Meeting of Transportation Research Board, Washington, 11-15 January, 21

19. Gustafson P (2012) Travel time and working time: what business travellers do when they travel, and why? Time Soc 21(2):203-222

20. Hamed M, Mannering F (1993) Modelling travellers post-work activity involvement : toward a new methodology. Transp Sci 27(4):381-394

21. Hesse-Biber SN (2010) Mixed methods research: merging theory with practice. Guilford 242

22. Hubert JP (2009) Dans les grandes agglomérations, la mobilité quotidienne des habitants diminue, et elle augmente ailleurs. Insee Premiere 1252

23. Hubert J-P, Toint P (2002) La mobilité quotidienne des Belges. Namur Presse Univ Namur 352

24. JAIN J, LYONS G (2008) The gift of travel time. J Transp Geogr $16: 81-89$

25. Joly I (2006) Stability of regularity of the daily travel time in Lyon? Application of a duration model. Int J Trans Econ 3:369-400, XXXIII

26. Joly I, Littlejohn K, Kaufmann V (2006) La croissance des budgetstemps de transport en question: nouvelles approches. PREDIT research report GO1 232

27. Kahneman D, Krueger AB, Schkade D, Schwarz N, Stone AA (2006) Would you be happier if you were richer? A focusing illusion. Science 312(5782):1908-1910
28. Kaufmann V (2008) Les paradoxes de la mobilité, Bouger, s'enraciner. Presses polytechniques et universitaires romandes, Lausanne

29. Kesselring S (2006) Pioneering mobilities: new patterns of movement and motility in a mobile word. Environ Plan A 38:269-279

30. Kitamura R, Chen C, Narayanan R (1998) The effects of time of day, activity duration and home location on traveller's destination choice behaviour. 77th Annual Meeting of the Transportation Research Board, Washington, 11-15 January, 25

31. Kitamura R, Robinson J, Golob TF, Bradley M, Leonard J, van der Hoorn T (1992) A comparative analysis of time use data in the Netherlands and California. Report UCD-ITS-RR-92-9, Institute of Transportation Studies, University of California, June, 127-138

32. Kvale S, Brinkmann S (2008) Interviews: learning the craft of qualitative research interviewing. Sage Publications Incorporated

33. Laurier E (2004) Doing office work on the motorway. Theory Cult Soc 21(4/5):261-277

34. Lawless JF (2003) Statistical models and methods for lifetime data. Wiley, New York

35. Lu X, Pas E (1999) Socio-demographics, activity participation and travel behaviour. Transp Res A 33(1):1-18

36. Lyons G, Jain J, Susilo Y, Atkins S (2013) Comparing rail passengers' travel time use in Great Britain between 2004 and 2010. Mobilities 8(4):560-579

37. Lyons G (2009) The reshaping of activities and mobility through new technologies. Editorial for special issue on ICT and the shaping of access, mobility and everyday life. J Transp Geogr 17(2):81-82

38. Ma J, Goulias KG (1998) Forecasting home departure time, daily time budget, activity duration and travel time using panel data. The 77th Annual Meeting of Transportation Research Board, Washington, 11-15 January, 29

39. Maoh H, Tang Z (2012) Determinants of normal and extreme commute distance in sprawled midsize Canadian city: evidence from Windsor, Canada. J Transp Geogr 25:50-57

40. Marion B, Horner M (2007) A comparison of the socioeconomic and demographic profiles of extreme commuters in several US metropolitan statistical areas. Transp Rese Rec 2013:38-45

41. Meissonnier J (2001) Provinciliens: Les voyageurs du quotidien, entre capitale et province. L'Harmattan, Paris

42. Mokhtarian PL, Chen C (2004) TTB or not TTB, that is the question: a review and analysis of the empirical literature on travel time (and money) budgets. Transp Res A 38(9-10):643-675

43. Mokhtarian PL, Salomon I (2001) How derived is the demand for travel? Some conceptual and measurement considerations. Transp Res A 35(8):695-719

44. Mokhtarian PL, Salomon I (1997) Modeling the desire to telecommute: the importance of attitudinal factors in behavioral models. Transp Res A 31(1):35-50

45. Oakes D (1977) The asymptotic information in censored survival data. Biometrika 64:441-448

46. O'fallon C, Wallis I (2012) A wider look at how travellers value the quality and quantity of travel time. New Zealand Transport Agency research report 469,128

47. OFS (2007) La mobilité en Suisse, Résultats du microrecensement 2005 sur le comportement de la population en matière de transports. Office fédéral du développement territorial et Office fédéral Statistique de la Suisse, Neuchâtel, 100

48. ONS (2013) Commuting and personal well-being, 2014. Office for National Statistics, Office for National Statistics (UK) report, 25p

49. Papon F, Armoogum J, Diana M (2008) Specific experimental trials versus large-scale mobility surveys insets to investigate transportrelated behavioural issues: the case of the primary utility of travel. ISCTSC Conference, Annecy

50. Redmond L, Mokhatarian P (2001) The positive utility of the commute: modelling ideal commute time and relative desired commute amount. Transportation 28(2):179-205 
51. Rocci A (2007) De l'automobilité à la multimodalité ? Analyse sociologique des freins et leviers au changement des comportements vers une réduction de l'usage de la voiture. Le cas de la région parisienne et perspective internationale. Thèse de doctorat en sociologie sous la direction de D. Desjeux, Université René Descartes, Sorbonne

52. Russel M (2012) Travel time use on public transport: what passengers do and how it affects their wellbeing. Phd thesis, University of Otago, Dunedin New Zealand, p343

53. Russell M, Price R, Signal L, Stanley J (2011) What do passengers do during travel time? Structured observations on buses and trains. J Public Transp 14(3):123-146

54. Schwanen T, Dijst M (2002) Travel-time ratios for visits to the workplace: the relationship between commuting time and work duration. Transp Res A 36:573-592

55. Srinivasan KK, Guo Z (2007) Analysis of trip and stop duration for shopping activities: Simultaneous hazard duration model system. Transp Res Rec 1854

56. Stutzer A, Frey BS (2008) Stress that doesn't pay: the commuting paradox. Scand J Econ 110(2):339-366
57. Timmermans H, Waerden P, Alves M, Polak J, Ellis S, Harvey AS, Kurose S, Zandee R (2002) Time allocation in urban and transport settings: an international, inter-urban perspective. Transp Policy 9(2):79-93

58. Tucci G (2006) Mixed methods and simulation research designs. Int J Transp Econ 33(3):301-311

59. Vincent S (2008) Les « altermobilités »: analyse sociologique d'usages de déplacements alternatifs à la voiture individuelle. Des pratiques en émergence? Phd thesis, Université Paris 5 - René Descartes, 416

60. Vincent-Geslin S (2010) Why spending two hours a day commuting? Deciding to become a long-distance commuter. Paper presented at the 12th WCTR, Lisbon

61. Watts L, Urry J (2008) Moving methods, travelling times. Environ Plann D Soc Space 26(5):860-874

62. Wee B, Rietveld P, Meurs H (2006) Is average daily travel time expenditure constant? In search of explanations for an increase in average travel time. J Transp Geogr 14(2):109-122 